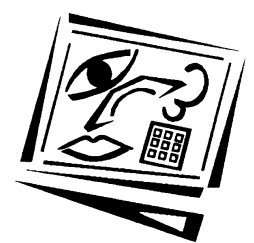

\title{
Relating use of digital technology by pre-service teachers to confidence: A Singapore survey
}

\author{
Alexander Seeshing Yeung \\ University of Western Sydney \\ Kam Ming Lim, Eng Guan Tay, Audrey Cheausim Lam-Chiang \\ and Chenri Hui \\ Nanyang Technological University
}

\begin{abstract}
Teachers today are expected to be able to apply a wide range of digital technologies in the classroom. Initial teacher education programs should prepare teachers to apply them with confidence. Pre-service teachers in Singapore responded to a survey on use of technologies in their personal lives and in their teaching, and how confident they were in using them. Among 17 applications, the most frequently used were those related to computer technology such as checking an online dictionary, web browsing and searching, emailing, and using computer software. Participants' use of computer software was frequent; however it was more so in their personal lives than in their teaching. The least used items included audio recording, video recording and global positioning system (GPS). Usage was found to be positively correlated with confidence, and while participants often had confidence in using the applications, their confidence was relatively low for items such as video and audio recording which they used the least. While teachers' use of computers is important, their ability and confidence to use other modern technologies for effective teaching should not be neglected.
\end{abstract}

\section{Introduction}

Teachers today are expected to be able to apply a wide range of digital technologies in their work (Graham, 2008; Roland, 2010; Todorova \& Osburg, 2009). Digital technology for educational purposes includes a variety of digital software and hardware used in learning and teaching processes within and beyond school settings (Davidson \& Goldberg, 2009; Lee \& Gaffney, 2008; Lee \& Winzenried, 2009). Digital technology is assumed to be able to help teachers optimise the oucomes of teaching and learning. The most often used digital media in a school setting include computers, digital cameras, scanners, online social networks, e-books, games, etc, in addition to some other forms of technology such as audio recorders, video recorders, calculators, etc. (Annetta, 2008; Roland, 2010). From this list, it can be seen that the term digital technology covers a wide range of tools that we use for a variety of purposes. For the purposes of teaching, teachers are likely to choose those that they are conversant with. Hence in order to facilitate teachers to use such technologies, initial teacher training programs should provide opportunities for trainees to experience various applications and to develop their competence in using them. To better enable teacher trainers to target essential technologies and prepare teachers to apply them with confidence, we need to identify those technologies that teachers use often and to understand whether 
they are confident in using them. The purpose of the present study is to identify, from a range of digital technologies, the most often and least often used ones, and the level of confidence that teachers under training in initial teacher education programs may hold. The results will guide us to focus on relevant digital technologies that need attention in initial teacher training.

\section{Digital technologies that teachers use}

In a classroom context, the term "digital technology" may include a range of media that teachers may use to optimise the effects of teaching and learning. Following Swan, Lin and van 't Hooft (2008), we use the term "digital technology" to "encompass the wide range of new tools that are being introduced in classrooms...; tools such as digital audio and video, mobile devices, podcasting, student response systems, computer-mediated communications, and Internet applications" (p. 171). Some of the technologies are computer-related whereas some others are not (Annetta, 2008; Roland, 2010). For example, forms of digital technology such as calculators, smart phones, and GPS, which teachers may use for their personal daily life, may not be directly computer-related. For learning purposes, one of the most used media is computer technology, which is believed to help learners master new knowledge and skills through access to an almost unlimited range of resources at any time in any place (Ferdig \& Boyer, 2007; Stevenson, 2008; Swan, van 't Hooft, Kratcoski \& Schenker, 2007).

Despite the known advantages of digital technology and the use of it in many professions and trades worldwide, the diffusion of digital technology in schools is not so evident in most countries (Warschauer \& Grimes, 2008). Although teachers and students seem to value digital technology and they believe it is a tool for facilitating teaching and learning, some teachers do not often use it for teaching. Even when it is used in classroom activities, such activities do not necessarily capitalise on the strengths of the technologies, learning processes tend to be superficial, and technologies may be applied for the sake of technology application per se. As such, the use of technology in the classroom may not really lead to substantial academic gains (Warschauer \& Grimes, 2008). This may be partly due to the teachers' lack of confidence in using the technology, or a lack of competence in making the best use of it to yield desirable effects. It may be partly due to the form of assessment that does not have any relevance for the purpose of technology application.

Teachers today, like other people in the modern world, use a wide range of digital technologies. Some of these forms of technology are rapidly changing. For example, analogue recordings on magnetic tape or on photographic film have been almost completely replaced by digital recording within a short span of 10 years. As such, as observed by Swan, Lin, and van 't Hooft (2008), teachers and teacher educators have to "constantly examine how they learn and how they help others learn to teach with technologies" (p. 172). This obviously poses challenges to teacher education. Considering teachers as individuals, different teachers have varying levels of competence and confidence in using new technologies. Whereas some teachers are competent with a wide range of technologies, some teachers may be competent in a few specific ones, whereas some others may not feel confident in using any technology at all (Kessler \& Plakans, 2008). However, whether they are competent or confident enough, teachers can hardly teach efficiently without any use of technology. As demonstrated by Robertson and Al-Zahrani (2012), pre-service teachers' self-efficacy 
perceptions increase with computer experiences and qualifications. Hence effective use of digital technology has become an essential component in the teacher education curriculum. Furthermore, the prevalence of digital technology, together with societal expectations, has shaped students' expectations of their teachers' application of technology in the classroom (Todorova \& Osburg, 2009). "How often do teachers use digital technologies?" and "How confident are they in using them?" are important questions, the answers to which will provide teacher educators with directions for improving digital application in school settings.

\section{Confidence in applying digital technology}

A range of psychological variables are known to be related to use of technology. In teaching and learning, Wong, Teo and Russo (2012) reported that perceived usefulness, perceived ease of use, and attitude toward computer use positively influence the intention and actual behaviour of using computers. This finding is similar to other research in this area (e.g., Moran, Hawkes \& El Gayar, 2010; Pynoo, Devolder, Tondeur, van Braak, Duyck \& Duyck, 2011). Among various factors, a particularly important one is an individual's self-perceptions of competence in using the technology. Researchers have demonstrated that in a variety of learning situations, individuals' sense of competence has important impacts on subsequent behaviours and performances (e.g., Craven \& Yeung, 2008; Marsh \& Craven, 2006). If teachers have a positive view of the self in using technology, they will use it. Hence, confidence in using technologies is a precursor for actual applications.

In demonstrating the importance of a sense of competence in online learning, $\mathrm{Ng}$, Yeung \& Hon (2006) tested adult learners in an English language program using computer technology and online interactions. They found that students who perceived themselves as more competent had more favorable perceptions about their online interaction with the teacher. Pena and Yeung (2010) also provided evidence of the importance of a sense of competence. In a survey, they asked university students enrolled in a Spanish course about their competence in using the computer and how much they liked using the computer. The course was conducted through a blended learning environment, whereby course contents were delivered partly face to face and partly online. They showed that both competence and affect were positively correlated with students' satisfaction with the online mode but not with the face to face mode. That is, students who were either competent with or fond of computers tended to be more satisfied with online delivery. Their results suggest that when the application of digital technology is concerned, a sense of competence does matter. They concluded that there is a need for enhancing users' sense of competence to optimise learning and teaching through technology application.

Kessler and Plakans (2008) provide further evidence that shows the importance of a positive sense of competence. They tracked the computer applications of seven teachers at two universities in the USA. Some teachers used computer technology for language learning more than others. The researchers interviewed the teachers periodically so as to identify them into three categories: (a) less confident, (b) contextually confident, and (c) highly confident in using the technology. The results showed that the teachers who were highly confident applied computer technology to teach language more than those who were less confident. However, those teachers who were contextually confident used the technology most. Kessler and Plakans concluded that developing the confidence of teachers, especially contextualised 
confidence within certain teaching domains or certain types of technology, would be most for attaining actual technology application.

\section{The present investigation}

In the present study, we examined the various digital technologies that teachers in initial training programs may use. We attempted to investigate whether their actual use of certain technologies was commensurate with their confidence in using them. A survey was conducted and the relationship between frequency of use and confidence of use was explored using correlation analysis and means comparisons. We expected that teachers' actual use of a certain technology would be positively correlated with teachers' confidence in using it. That is, teachers who feel confident in using a digital technology (e.g., confidence in emailing) would more often engage themselves in the technology (i.e., frequency of emailing in this case).

We also attempted to identify which items were most used and which were least used, as well as which items were those that teachers were least confident with. The list of technologies included those in personal use and those that are relevant to classroom teaching and learning activities; and those that are relatively new and others that have existed for a long time in school settings. The patterns are compared between preservice teachers from two different pre-service programs with a clear between-group difference in terms of age. Based on Duncan-Howell (2012) who found that irrespective of age and life experience, pre-service teachers shared a similar "digital expectation and they expect upon completion of their studies to be more digitally fluent" (p. 827), we expected similar patterns across groups. The findings of this study will hopefully provide us with directions as to which technologies we should accord more attention in teacher education programs, so as to help teachers of the new generation to function more effectively in the classroom.

\section{Method}

\section{Participants}

The participants were pre-service teachers enrolled in two different teacher education programs with the National Institute of Education (NIE), Nanyang Technological University, in Singapore. Invitations to participate in the survey were sent to 394 preservice teachers from the 1-year Postgraduate Diploma in Education for secondary teachers (PGDE) in April 2010, and 244 Year 3 student teachers from the 4-year undergraduate program in August 2010. The response rates were 42\% (164 responses out of 394 invitations) for the PGDE program and 66\% (160 responses out of 244 invitations) for the degree program (total $N=324$ for the analysis). There were $58 \%$ female and $42 \%$ male participants from the PGDE program and they came from 29 different subject disciplines. There were $74 \%$ females and $26 \%$ males from the degree program and they came from 19 different disciplines. The age range of the PGDE students was 22-48 years old (median age $=26$ ), whereas the degree students were younger, ranging from 21 to 29 years old (median age $=22$ ). All participants speak English, in which the survey was conducted. Whereas there are four major languages in Singapore (English, Mandarin, Malay, and Tamil), English and Malay are the official languages used in the government, and English is also the most commonly used language for communication. 
NIE not only equips the campus with digital technology facilities to support learning and teaching, it also provides every pre-service teacher (including those who participated in the study) with a laptop computer for use throughout the course of their study. These provisions aim to enable the pre-service teachers to be enveloped in a technological environment and enhance their effectiveness in using digital technology early in their teaching careers.

\section{Material and procedure}

The survey instrument was piloted with non-participants in this study before it was used with the current participants. There were 17 items asking them about their applications of digital technologies (Tables 1 and 2). Nine were clearly about computer technology whereas eight were about digital technologies that do not necessarily involve computers. For example, GPS does not require daily use of computers except when updating information. The participants were asked to rate on a scale of 1 (never) to 6 (always) on these digital technologies. An open-ended question was also included for the participants to report any other digital technologies they had used that were not on the list. Background variables included age, gender, and language background.

Table 1: Frequencies of applications for PGDE students

\begin{tabular}{|c|c|c|c|c|c|c|}
\hline Digital technology & $\begin{array}{c}\text { Never } \\
1\end{array}$ & 2 & 3 & 4 & 5 & $\begin{array}{c}\text { Always } \\
6\end{array}$ \\
\hline Emailing & $1.2 \%$ & $0.0 \%$ & $4.3 \%$ & $13.4 \%$ & $24.4 \%$ & $56.7 \%$ \\
\hline Web browsing and searching & $1.2 \%$ & $0.0 \%$ & $4.3 \%$ & $15.9 \%$ & $29.9 \%$ & $48.8 \%$ \\
\hline Using computer software for personal use & $1.2 \%$ & $3.0 \%$ & $11.0 \%$ & $23.8 \%$ & $20.7 \%$ & $40.2 \%$ \\
\hline Using a calculator & $0.6 \%$ & $6.7 \%$ & $25.6 \%$ & $24.4 \%$ & $18.9 \%$ & $23.8 \%$ \\
\hline Checking an online dictionary & $1.8 \%$ & $4.9 \%$ & $23.8 \%$ & $29.9 \%$ & $15.2 \%$ & $24.4 \%$ \\
\hline Photo taking & $0.6 \%$ & $4.3 \%$ & $26.2 \%$ & $37.8 \%$ & $15.2 \%$ & $15.9 \%$ \\
\hline Online chatting (e.g. MSN) & $6.1 \%$ & $10.4 \%$ & $22.0 \%$ & $17.7 \%$ & $17.7 \%$ & $26.2 \%$ \\
\hline Using computer software for teaching & $1.8 \%$ & $9.1 \%$ & $26.2 \%$ & $30.5 \%$ & $23.8 \%$ & $8.5 \%$ \\
\hline Using smart phones (e.g. iPhone, Blackberry) & $20.7 \%$ & $11.6 \%$ & $12.2 \%$ & $11.0 \%$ & $15.9 \%$ & $28.7 \%$ \\
\hline Checking digital calendar/organiser & $11.0 \%$ & $19.5 \%$ & $18.3 \%$ & $18.3 \%$ & $14.0 \%$ & $18.9 \%$ \\
\hline Checking Google Maps & $11.0 \%$ & $18.3 \%$ & $29.9 \%$ & $23.8 \%$ & $11.0 \%$ & $6.1 \%$ \\
\hline Playing online/computer games & $11.0 \%$ & $22.6 \%$ & $33.5 \%$ & $14.0 \%$ & $9.8 \%$ & $9.1 \%$ \\
\hline Blogging & $18.3 \%$ & $31.1 \%$ & $20.1 \%$ & $14.6 \%$ & $7.9 \%$ & $7.9 \%$ \\
\hline Reading electronic books & $15.2 \%$ & $27.4 \%$ & $33.5 \%$ & $12.8 \%$ & $4.9 \%$ & $6.1 \%$ \\
\hline Video recording & $7.3 \%$ & $36.6 \%$ & $31.1 \%$ & $20.1 \%$ & $3.7 \%$ & $1.2 \%$ \\
\hline Global positioning system (GPS) & $28.0 \%$ & $24.4 \%$ & $22.6 \%$ & $14.0 \%$ & $7.3 \%$ & $3.7 \%$ \\
\hline Audio recording & $8.5 \%$ & $51.8 \%$ & $32.3 \%$ & $6.1 \%$ & $0.6 \%$ & $0.6 \%$ \\
\hline
\end{tabular}

Note: $N=164$. Other activities mentioned by students in the program included: Facebook, online

shopping, online TV, singing, social networking, watching videos, and webcamming.

Procedures approved by the University's ethics committee were followed. The data collection was done online. The project team announced in the NIE Student Portal to the targeted groups of pre-service teachers the up-coming online survey and invited them to participate. An email was sent, which explicitly described the study and its aim: "to develop an understanding of the extent to which NIE students value and engage with digital technologies in support of their Initial Teacher Preparation (ITP)". The approximate duration of the survey (no more than 20 minutes) and the project officer's contact details were also provided. The data were downloaded into the SPSS statistical software for analysis. 
Table 2: Frequencies of applications for Bachelor's Degree students

\begin{tabular}{|c|c|c|c|c|c|c|}
\hline Digital technology & $\begin{array}{c}\text { Never } \\
1 \\
\end{array}$ & 2 & 3 & 4 & 5 & \begin{tabular}{|c} 
Always \\
6 \\
\end{tabular} \\
\hline Emailing & $0.6 \%$ & $0.6 \%$ & $1.9 \%$ & $15.6 \%$ & $20.6 \%$ & $60.6 \%$ \\
\hline Web browsing and searching & $0.6 \%$ & $0.0 \%$ & $4.4 \%$ & $12.5 \%$ & $16.9 \%$ & $65.6 \%$ \\
\hline Using computer software for personal use & $1.3 \%$ & $5.0 \%$ & $13.8 \%$ & $21.3 \%$ & $15.0 \%$ & $43.8 \%$ \\
\hline Using a calculator & $1.9 \%$ & $11.9 \%$ & $19.4 \%$ & $19.4 \%$ & $19.4 \%$ & $28.1 \%$ \\
\hline Checking an online dictionary & $0.6 \%$ & $1.3 \%$ & $10.0 \%$ & $28.8 \%$ & $26.9 \%$ & $32.5 \%$ \\
\hline Photo taking & $0.0 \%$ & $3.1 \%$ & $17.5 \%$ & $27.5 \%$ & $27.5 \%$ & $24.4 \%$ \\
\hline Online chatting (e.g. MSN) & $1.9 \%$ & $4.4 \%$ & $12.5 \%$ & $17.5 \%$ & $20.6 \%$ & $43.1 \%$ \\
\hline Using computer software for teaching & $1.3 \%$ & $10.0 \%$ & $27.5 \%$ & $23.8 \%$ & $20.6 \%$ & $16.9 \%$ \\
\hline Using smart phones (e.g. iPhone, Blackberry) & $18.1 \%$ & $15.6 \%$ & $10.6 \%$ & $11.9 \%$ & $9.4 \%$ & $34.4 \%$ \\
\hline Checking digital calendar/organiser & $8.1 \%$ & $18.1 \%$ & $20.0 \%$ & $20.6 \%$ & $13.8 \%$ & $19.4 \%$ \\
\hline Checking Google Maps & $8.1 \%$ & $16.3 \%$ & $35.0 \%$ & $17.5 \%$ & $12.5 \%$ & $10.6 \%$ \\
\hline Playing online/computer games & $6.9 \%$ & $18.8 \%$ & $24.4 \%$ & $16.3 \%$ & $16.9 \%$ & $16.9 \%$ \\
\hline Blogging & $21.9 \%$ & $25.6 \%$ & $21.3 \%$ & $12.5 \%$ & $9.4 \%$ & $9.4 \%$ \\
\hline Reading electronic books & $16.3 \%$ & $26.3 \%$ & $23.1 \%$ & $20.0 \%$ & $6.3 \%$ & $8.1 \%$ \\
\hline Video recording & $6.3 \%$ & $33.1 \%$ & $28.1 \%$ & $20.0 \%$ & $7.5 \%$ & $5.0 \%$ \\
\hline Global positioning system (GPS) & $23.1 \%$ & $29.4 \%$ & $26.3 \%$ & $6.9 \%$ & $7.5 \%$ & $6.9 \%$ \\
\hline Audio recording & $6.9 \%$ & $43.8 \%$ & $35.6 \%$ & $8.8 \%$ & $3.1 \%$ & $1.9 \%$ \\
\hline
\end{tabular}

Note: $N=160$. Other activities mentioned by students in this program included: Facebook, gaming,

Skype, Twitter, video editing, and blogging.

\section{Statistical analysis}

For each of the 17 digital technologies, we examined the frequency of use and participants' confidence in using it. Percentages were presented for responses to the six-point scale (Tables 1 and 2). For frequency of use, respondents answered the question: "How often do you use it?" with the following scale: $1=$ never, $2=$ rarely, $3=$ occasionally, $4=$ often, $5=$ most of the time, and $6=$ always. For confidence, the same scale was used but the question was "How often do you feel confident in using it?" Hence higher scores reflected more often use of digital technology and higher confidence in using it, respectively.

For each pair of items regarding each of the 17 digital technologies (i.e., use and confidence), the mean scores were compared using a paired $t$-test. The correlation between the two variables was also reported. The correlation between variables would test the hypothesis that more frequent use of a technology would be related to more confidence in using it. A mean comparison between variables would inform us whether there are technologies that the participants use often but do not have the confidence in using them. By presenting the technologies in a rank order in terms of frequency of use, we would be able to observe which technologies have been more popular than other technologies and whether participants' confidence was commensurate with their application.

\section{Results}

\section{Frequency of use}

The frequency of use for each digital technology is presented in Table 1 for PGDE students and in Table 2 for degree students. The mean scores for use of, and confidence in, using each digital technology are presented in Table 3 for PGDE students and Table 4 for degree students, respectively. 
Table 3: Means, standard deviations, correlations, and differences between application and confidence of PGDE students

\begin{tabular}{|c|c|c|c|c|c|c|c|c|c|}
\hline \multirow{2}{*}{ Digital technology } & \multirow{2}{*}{$\begin{array}{l}\text { Rank } \\
\text { Use }\end{array}$} & \multirow{2}{*}{$\begin{array}{l}\text { Rank } \\
\text { Conf }\end{array}$} & \multicolumn{2}{|c|}{ Use } & \multicolumn{2}{|c|}{ Confidence } & \multirow{2}{*}{$r$} & \multirow{2}{*}{$t$} & \multirow{2}{*}{$\eta^{2}$} \\
\hline & & & Mean & $S D$ & Mean & $S D$ & & & \\
\hline Emailing & 1 & 1 & 5.30 & 0.99 & 5.28 & 1.19 & .40 & 0.19 & .00 \\
\hline Web browsing and searching & 2 & 2 & 5.20 & 0.99 & 5.12 & 1.29 & .40 & 0.74 & .00 \\
\hline $\begin{array}{l}\text { Using computer software for } \\
\text { personal use }\end{array}$ & 3 & 5 & 4.80 & 1.23 & 4.70 & 1.44 & .61 & 1.17 & .01 \\
\hline Using a calculator & 4 & 3 & 4.26 & 1.29 & 5.08 & 1.29 & .41 & $-7.53^{* *}$ & .26 \\
\hline Checking an online dictionary & 5 & 4 & 4.25 & 1.29 & 4.96 & 1.40 & .43 & $-6.25^{\star *}$ & .19 \\
\hline Photo taking & 6 & 7 & 4.10 & 1.13 & 4.53 & 1.36 & .54 & $-4.50^{* *}$ & .11 \\
\hline Online chatting (e.g. MSN) & 7 & 6 & 4.09 & 1.55 & 4.62 & 1.61 & .62 & $-4.89^{* *}$ & .13 \\
\hline $\begin{array}{l}\text { Using computer software for } \\
\text { teaching }\end{array}$ & 8 & 10 & 3.91 & 1.17 & 4.10 & 1.41 & .59 & $-2.11^{*}$ & .03 \\
\hline $\begin{array}{l}\text { Using smart phones (e.g. iPhone, } \\
\text { Blackberry) }\end{array}$ & 9 & 9 & 3.76 & 1.93 & 4.11 & 1.74 & .68 & $-3.08^{*}$ & .06 \\
\hline $\begin{array}{l}\text { Checking digital calendar/ } \\
\text { organiser }\end{array}$ & 10 & 8 & 3.62 & 1.65 & 4.24 & 1.67 & .67 & $-5.92^{* *}$ & .18 \\
\hline Checking Google Maps & 11 & 12 & 3.24 & 1.34 & 3.91 & 1.66 & .56 & $-5.96^{\star *}$ & .18 \\
\hline Playing online/ computer games & 12 & 13 & 3.16 & 1.42 & 3.88 & 1.63 & .64 & $-6.98^{* *}$ & .23 \\
\hline Blogging & 13 & 14 & 2.87 & 1.49 & 3.81 & 1.78 & .54 & $-7.57^{* *}$ & .26 \\
\hline Reading electronic books & 14 & 12 & 2.83 & 1.32 & 4.01 & 1.60 & .54 & $-10.75^{\star *}$ & .41 \\
\hline Video recording & 15 & 15 & 2.80 & 1.04 & 3.76 & 1.56 & .53 & $-9.19^{* *}$ & .34 \\
\hline Global positioning system (GPS) & 16 & 17 & 2.59 & 1.40 & 3.43 & 1.83 & .68 & $-7.96^{\star *}$ & .28 \\
\hline Audio recording & 17 & 16 & 2.40 & 0.80 & 3.63 & 1.51 & .39 & $-11.19^{* *}$ & .43 \\
\hline
\end{tabular}

Note: $N=164 . r$ = correlation between application and confidence. Paired $t$-tests were conducted

between application and confidence and $t$-values and effect sizes are reported. ${ }^{*} p<.05 ;{ }^{* *} p<.001$

Table 4: Means, standard deviations, correlations, and differences between application and confidence of Bachelor's Degree students

\begin{tabular}{|c|c|c|c|c|c|c|c|c|c|}
\hline \multirow{2}{*}{ Digital technology } & \multirow{2}{*}{$\begin{array}{c}\text { Rank } \\
\text { Use }\end{array}$} & \multirow{2}{*}{$\begin{array}{l}\text { Rank } \\
\text { Conf }\end{array}$} & \multicolumn{2}{|c|}{ Use } & \multicolumn{2}{|c|}{ Confidence } & \multirow{2}{*}{$r$} & \multirow{2}{*}{$t$} & \multirow{2}{*}{$\eta^{2}$} \\
\hline & & & Mean & $S D$ & Mean & $S D$ & & & \\
\hline Emailing & 2 & 1 & 5.37 & 0.93 & 5.41 & 1.11 & .55 & -0.57 & .00 \\
\hline Web browsing and searching & 1 & 2 & 5.42 & 0.94 & 5.29 & 1.16 & .72 & 1.96 & .02 \\
\hline $\begin{array}{l}\text { Using computer software for } \\
\text { personal use }\end{array}$ & 5 & 7 & 4.75 & 1.34 & 4.74 & 1.44 & .72 & 0.08 & .00 \\
\hline Using a calculator & 7 & 5 & 4.27 & 1.45 & 5.19 & 1.16 & .38 & $-7.91^{* *}$ & .29 \\
\hline Checking an online dictionary & 4 & 4 & 4.78 & 1.09 & 5.27 & 1.16 & .37 & $-4.96^{\star *}$ & .13 \\
\hline Photo taking & 6 & 6 & 4.53 & 1.13 & 4.87 & 1.17 & .52 & $-3.86^{\star *}$ & .09 \\
\hline Online chatting (e.g. MSN) & 3 & 3 & 4.80 & 1.33 & 5.27 & 1.22 & .51 & $-4.67^{* *}$ & .12 \\
\hline $\begin{array}{l}\text { Using computer software for } \\
\text { teaching }\end{array}$ & 8 & 10 & 4.03 & 1.30 & 4.19 & 1.43 & .66 & -1.82 & .02 \\
\hline $\begin{array}{l}\text { Using smart phones (e.g. iPhone, } \\
\text { Blackberry) }\end{array}$ & 9 & 12 & 3.82 & 1.96 & 4.03 & 1.76 & .73 & -1.94 & .02 \\
\hline $\begin{array}{l}\text { Checking digital calendar/ } \\
\text { organiser }\end{array}$ & 10 & 8 & 3.72 & 1.58 & 4.39 & 1.63 & .64 & $-6.18^{\star *}$ & .19 \\
\hline Checking Google Maps & 12 & 11 & 3.42 & 1.40 & 4.13 & 1.59 & .64 & $-7.06^{\star *}$ & .24 \\
\hline Playing online/ computer games & 11 & 9 & 3.68 & 1.54 & 4.34 & 1.55 & .57 & $-5.80^{* *}$ & .17 \\
\hline Blogging & 15 & 14 & 2.90 & 1.57 & 3.89 & 1.87 & .61 & $-8.06^{* *}$ & .29 \\
\hline Reading electronic books & 14 & 13 & 2.98 & 1.45 & 3.97 & 1.69 & .60 & $-8.78^{\star \star}$ & .33 \\
\hline Video recording & 13 & 15 & 3.04 & 1.24 & 3.84 & 1.50 & .64 & $-8.46^{\star *}$ & .31 \\
\hline Global positioning system (GPS) & 16 & 17 & 2.67 & 1.45 & 3.44 & 1.78 & .68 & $-7.35^{\star \star}$ & .25 \\
\hline Audio recording & 17 & 16 & 2.63 & 0.98 & 3.52 & 1.52 & .49 & $-8.38^{\star *}$ & .31 \\
\hline
\end{tabular}

Note: $N=160 . r$ = correlation between application and confidence. Paired $t$-tests were conducted between application and confidence and $t$-values and effect sizes are reported. ${ }^{*} p<.05 ;{ }^{* *} p<.001$ 
The technologies are rank ordered by the mean scores such that the most often used are placed at the top and the least used at the bottom of the respective table (Tables 3 and 4). For the PGDE students (Table 3), the most often used technologies were emailing, web browsing and searching, using computer software for personal use, using a calculator, checking an online dictionary, photo taking, and online chatting (means $>4$ on a 6-point scale; Table 3). All these items were reported by over $60 \%$ of the PGDE students to be often used (Table 1). The most frequently used items for degree students were also identical (means $>4$ on a 6-point scale; Table 4 ), and again, these items were reported by over $60 \%$ of the degree student to be often used (Table 2). Although the rank order in terms of frequency of use was a little different between PGDE and degree students, these seven digital technologies were ranked as the top seven for both groups (Tables 3 and 4).

For the PGDE students the least used items were: blogging, electronic books, video recording, GPS, and audio recording (means $<3$ on a 6-point scale; Table 3), with above $60 \%$ reporting occasional use or less (Table 1). The same five items were found to be also used least by degree students, although the means seem to be a little higher than for PGDE students, but also with above $60 \%$ reporting occasional use or less (Table 2 ).

Using computer software for teaching (means=3.91 and 4.03) was in between the most and least used items (Tables 3 and 4). Between computer software for personal use (mean=4.80) and computer software for teaching (mean=3.91) for PGDE students, there was clearly a large gap (Table 3). A similarly noticeable gap was observed for degree students (means $=4.75$ vs. 4.03 , respectively). The data show that pre-service teachers may not use computer software for teaching as much as they do for their personal use.

\section{Confidence in using digital technology}

The most frequently used digital technologies were found to be also those that the participants had the highest confidence in using (Tables 3 and 4), although the rank order may not be identical. The bottom three technologies in terms of frequency of use were also those in which the participants had the lowest confidence in using (Tables 3 and 4). These patterns were consistent across the PGDE and degree students.

\section{Relationship between use and confidence}

Participants' rate of use of a certain technology may be related to their confidence in using it. The comparable patterns found in Tables 3 and 4 showing that the rank order for confidence is very similar to the rank order for frequency of use indicate that for both groups of students, those who used a certain technology more also tended to have higher confidence in using it. For example, the top two frequently used technologies (emailing and web browsing) were also technologies in which the participants reported greatest confidence. At the low end, GPS and audio recording were the least used and they were technologies in which the participants were least confident. The correlations between confidence and use of technology are also consistent with this finding. The correlations between use and confidence were all positive and significant ( $r$ values ranging from .39 to .68 for PGDE, and from .38 to .73 for degree students). If the 17 items of application were treated as a composite variable of application and the 17 items of confidence were treated as a composite variable of confidence, the overall correlation between application and confidence was found to be .61. The scatter plot in Figure 1 reveals a strong positive relationship between use of DT and confidence for 
both the degree students and PGDE students. In essence, those individuals who were confident in using a certain technology tended to use that technology more, and those who used a certain technology tended to be confident in using it.

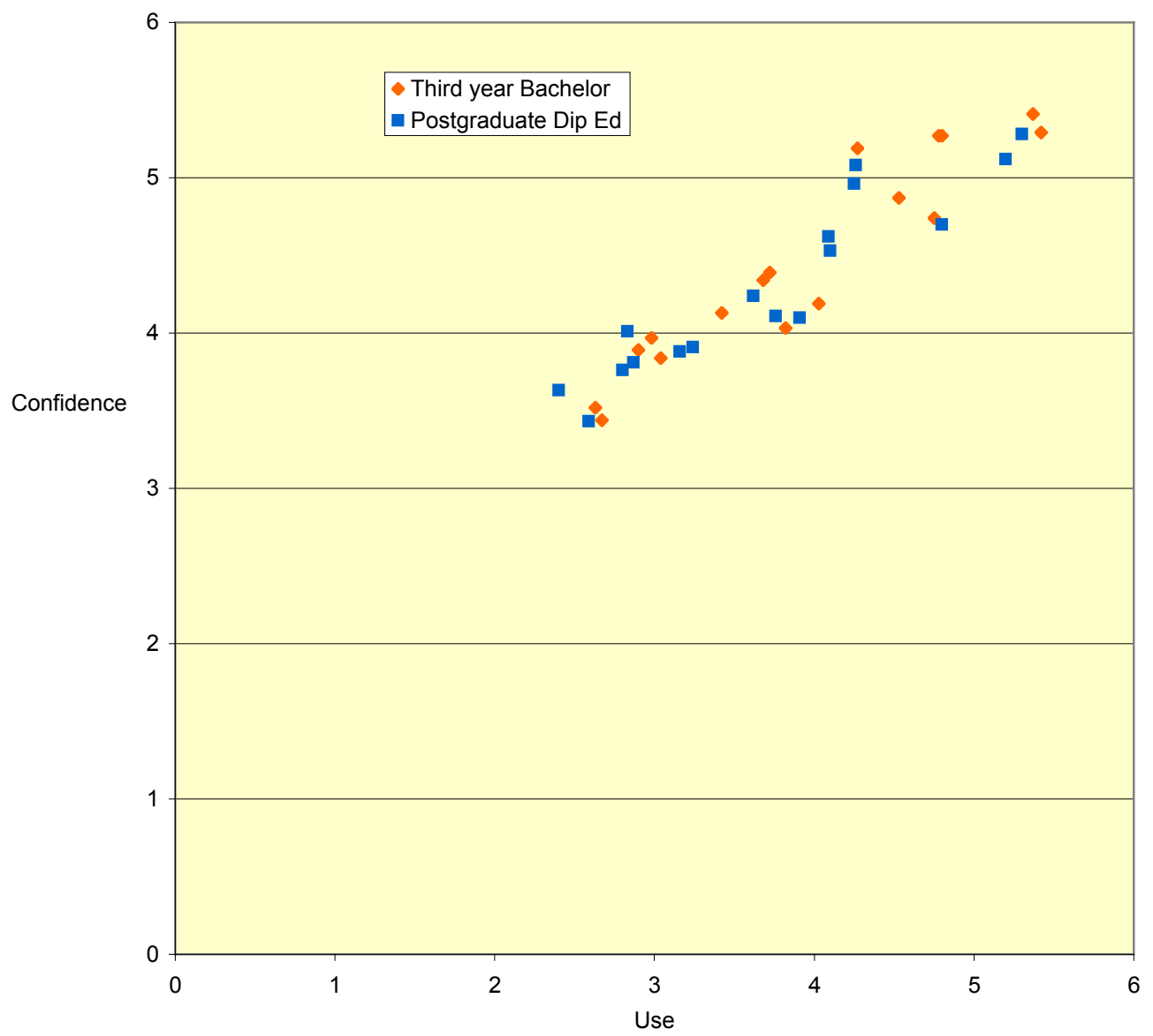

Figure 1: Plot of the relationship between use of digital technology and confidence

\section{Application-confidence discrepancy}

To examine whether there was a discrepancy between actual use of a specific digital technology and confidence in using it, a $t$-test was conducted between application and confidence scores (i.e., a repeated-measures comparison). An inspection of the mean scores of application and confidence found a general pattern of higher confidence scores than actual use for most items (except for the top frequently used items). That is, the participants had generally high confidence in using most of the digital technologies listed.

Specifically for PGDE, the discrepancy between use and confidence was not statistically significant and was negligible for most often used technologies on the top of the list including emailing, $t(163)=0.19$, web browsing and searching $t(163)=0.74$, and computer software for personal use $t(163)=1.17$. For the other technologies, the 
discrepancy between actual use and confidence was statistically significant for every item, favouring confidence. That is, the participants had higher confidence than their actual use of the technologies. The same pattern was found also with the degree students. The difference between use and confidence was negligible for those technologies on the top of the list: emailing, $t(159)=-0.57$, web browsing and searching $t(159)=1.96$, and using computer software for personal use $t(159)=0.08$. For the other technologies, again the difference was statistically significant for every item, favouring confidence.

Nevertheless, for some of the technologies, the discrepancy was small although statistically significant (Tables 3 and 4). For example, the difference between actual use of computer software for teaching (means=3.91 and 4.03 for PGDE and degree, respectively) and confidence in using computer software for teaching (means $=4.10$ and 4.19 , respectively) was statistically significant $(p<.05)$. However, the effect sizes were small $\left(\eta^{2}<.03\right)$ and may not have strong practical implications.

\section{Group differences}

A 2 group (PGDE vs. Degree) $\times 2$ measure (use vs. confidence) repeated-measures ANOVA found a small but statistically significant main effect of group, $F(1,322)=4.67$, $M S E=1.15, p<.05, \eta^{2}=.01$, indicating that the students in the degree program had more frequent use $(M=3.93, S D=0.68)$ and higher confidence in using digital technology $(M=4.30, S D=0.91)$ than the students in the PGDE program $(M=3.72, S D=0.71$ and $M=4.15, S D=1.08$ for use and confidence, respectively). The main effect of the withinsubjects factor was also statistically significant, $F(1,322)=77.25, M S E=0.34, p<.001$, $\eta^{2}=.19$, indicating that for both teacher education programs, students had higher confidence than their use in digital technology. The group $\times$ measure interaction effect was not statistically significant, $F(1,322)=0.48, M S E=0.345, p>.05, \eta^{2}=.00$, indicating that the group differences were consistent between measures, and the difference between measures were also consistent across groups.

\section{Discussion}

In this study, we examined pre-service teachers' use of a wide range of digital technologies and their confidence in using them. The two groups were different in age and work experience. The PGDE students were degree holders who were typically older and more experienced. The students in the bachelor's degree program were younger and less experienced. Across these two pre-service teacher education programs, the pattern of use in terms of frequency was very similar. In essence, many computer-related technologies were most frequently used (e.g., emailing, web browsing, using computer software for personal use, and checking online dictionary), except for using a calculator, which was one on the top of the list but was unrelated to computer technology. More importantly, although the younger participants (those in the degree program) may use these technologies more frequently, the top ranking of these technologies is common across the two groups.

The least used technologies (the bottom items in Tables 3 and 4) included not only those that have come into existence just recently (e.g., e-books, blogging, and GPS), but they also included some of the oldest technologies that have existed for decades or even for a century (e.g., video recording and audio recording - although these have become digital nowadays). The low frequency of use for the emerging technologies 
may be related to a lack of exposure to and understanding of these new technologies, and hence a low frequency of application. There may also be limited access to such technologies or they are not a necessary tool in the life of most of these participants. For example, GPS may not be a relevant technology to the degree students who are younger and may not be drivers. Therefore, they may not find the GPS technology useful. However, the low frequency of use for video recording and audio recording may not be readily explainable. Given the long history of existence, we would expect that they would be used more and the users should have good confidence in using them. Although such technologies have changed a lot in the digital era, given the much cheaper, much easier, and more efficient recording and editing functions, we might expect more frequent use. Nevertheless, the data showed otherwise. For both PGDE and degree programs, both actual use and confidence in these technologies were relatively lower than other technologies. If we believe that the principles underlying good pedagogical designs using long-existing technologies in earlier times continue to be relevant, then the younger generation of teachers may need to adapt these good design principles to optimise learning benefits by taking advantage of the cheapness and efficiency of such technologies today. For example, teachers and students are able to produce their own audio-visual resources and meaningful learning activities can be easily designed around this flexibility, which was not imaginable in the olden days.

The consistency of the patterns found between the older and younger subsamples is worth noting. The consistency implies that pre-service teachers may have similar needs and expectations, irrespective of age and experience. Teachers, irrespective of age and experience, are expected to be able to apply a wide range of digital technologies in today's classrooms (Graham, 2008; Roland, 2010; Todorova \& Osburg, 2009). This ability enables them to optimise learning and teaching processes within and beyond school settings (see Lee \& Gaffney, 2008; Lee \& Winzenried, 2009; Davidson \& Goldberg, 2009). In order to facilitate teachers to use technologies effectively, we need to identify which technologies teachers will use most often and least often. It is also important to identify which technologies they are not so confident in using.

Often influencing teachers' use of technology is their self-perceptions of competence in using it. An individual's sense of competence is known to have important impacts on subsequent behaviours and performances (e.g., Craven \& Yeung, 2008; Marsh \& Craven, 2006). Hence teachers who have a positive sense of competence in using technology are more likely to use it. In contrast, those who do not have confidence in using a certain technology are unlikely to engage themselves in teaching and learning activities that involve it. As such, teachers' confidence and their actual use of technologies would be expected to correlate positively with each other. Our data have supported this hypothesis. Hence, consistent with Kessler and Plakans (2008), Ng et al. (2006) and Pena and Yeung (2010), positive perceptions about the self is significantly correlated to active use of technologies.

Many professions worldwide have been using various kinds of technology, but the application of digital technology in schools is still less than optimal (Warschauer \& Grimes, 2008). It is surprising that although teachers seem to value digital technology, they do not often use it for teaching. Our data showed that the pre-service teachers in our sample were mostly confident in using a wide range of technologies, but their actual use of the technologies was not as high. Two major observations could be made from the consistent patterns of the present data across the two programs: (1) use and confidence are positively related, and (2) confidence is higher than actual use. The first 
observation implies that the more confidence in using a certain technology, the more likely the teacher will use it for teaching. This means that by enhancing teachers' confidence in using a certain technology, chances are that they will use it more often. However, the second observation implies that the teachers are not lacking in confidence and therefore the low frequency of use for some technologies may not be totally attributed to a lack of confidence. In fact, it may only be a matter of choice among numerous usable technologies. Given limited time to engage oneself with a range of daily used technologies, the reality is that none of the technologies would receive sufficient attention.

Although the findings suggest that teachers generally have a high level of confidence in using technology, their use is stronger for personal purposes than for teaching purposes. This mismatch between personal use of technology and classroom applications is probably a concern to policy makers and teacher educators. Multiple reasons might account for this mismatch. Ertmer (1999) suggests that there are two types of factors that may hinder efforts towards integrating technologies. The first category refers to external barriers which include issues of adequate facilities, access, training and support. The second category refers to teachers' philosophy and beliefs about teaching and learning.

For the first category, the less than optimal use of technology in teaching may be due to the lack of a coherent leadership and organisational structure that support and encourage the use of technology for teaching (Divaharan \& Lim, 2010). In 1997, the Ministry of Education, Singapore, embarked on an ICT Masterplan to establish, initiate and facilitate technological integration in curriculum, assessment and pedagogy. The first phase of the ICT Masterplan dealt with the provision of basic ICT facilities and infrastructure, as well as attainment of core technological skills in students and teachers (Koh \& Lee, 2008). Hence to date, primarily the first category of hindrance in the form of external factors has been addressed.

The second phase of the ICT Masterplan (2003 to 2008) attempted to encourage teachers' adoption of a learner-centric pedagogy and schools to flexibly implement ICT innovations (Koh \& Lee, 2008). The Ministry of Education is now in the midst of the third phase of the ICT Masterplan which is focused on developing students' 21st century competencies (e.g., collaboration skills) and integration of ICT in curriculum, assessment and pedagogy for such development (Ministry of Education Singapore, 2010). Although Singapore school principals have a very positive attitude toward the use of technology in education, with an average score of 90 out of 100 (Koh \& Lee, 2008), not all schools have a clear ICT implementation plan and structure (Divaharan \& Lim, 2010). In essence, whilst the second and third phases focused more on the users and their beliefs and practices, it seems that more work is needed to bring about changes in actual behaviour and practice.

Users' beliefs and perceptions do make a difference in their use of technology (Yeung, Taylor, Hui, Lam-Chiang \& Low, 2012). One persistent hindrance to technology application in schools is teachers' perceived lack of time (Dawson \& Heinecke, 2004; Dias, 1999; Ertmer, 1999; Lim \& Khine, 2006; Wang \& Chan, 1995). This is partly a first category factor (i.e., timetable constraints, which is external), and partly a second category factor (i.e., beliefs). While teachers do have the knowledge and skills to use innovative pedagogies, which include intensive use of technology, many of them would gravitate back towards the use of traditional modes of teacher-centred 
pedagogy (Lim \& Khine, 2006).This is due not only to time and resource constraints, but also due to teachers' belief that traditional pedagogical approaches are more efficient in terms of curriculum coverage. Further complicating the issue, as Egan and FitzGibbon (2010) have shown, some student teachers do not seem to have a good mastery of the application of technology for teaching, despite completing an intensive course on the use of technology as part of their teacher education program. As such, it may not be easy for teachers to adopt comfortably risk-taking behaviours such as innovative use of technologies (Yeung et al., 2012). Furthermore, teachers also reported hesitations about having their ICT integrated pedagogies evaluated (Lim \& Khine, 2006).

\section{Limitations}

This study has several limitations. First, the study relied on self-reporting. Although the use of self-reported data has been accepted as a reliable methodology in the research literature (Gonyea, 2005), caution is advised in the interpretation of the data. To provide richer data, future research may consider including also measures of both teachers' and students' expectations of digital technology application and relating them to self-efficacy scores. Secondly, the study investigated a sample of pre-service teachers. Their usage of technology may change as they progress through their teaching career. As they gain more experience in understanding the system-level support and organisational constraints in the use of various forms of technology to enhance teaching and learning, their level of motivation and usage of such technology may change (Demetriadis et al., 2003). It may be useful for future studies to follow-up on the attitudes and usage of technology in education as pre-service teachers' progress through their teaching career. In this sense, longitudinal studies will be worthwhile.

\section{Conclusion}

To conclude, we may speculate that the younger generation of teachers will be using a variety of modern digital technologies increasingly. However, the most popular technologies are likely to be computer-related, and some long-existing technologies may be somewhat neglected. Whereas newly emerging technologies need attention, the long-existing technologies that have proved to benefit learning should not be ignored. It is also important to find ways to encourage pre-service teachers to use technologies for teaching and learning purposes. Our data showed that personal use of computer software is far more popular than application in the classroom. This implies that technology application is at a less-than-optimal level. It is not only important to build up the teachers' confidence in technology applications, as they seem to already have good confidence in the technologies, but also to guide them to see the relevance of the technologies in a teaching and learning environment (Teo, 2008).

\section{Acknowledgment}

This research entitled 'Building an Evidence-base for Initial Teacher Preparation (ITP) in the National Institute of Education (NIE): A Formative Project', was supported by the Office of Education Research under a Singapore Ministry of Education research grant (OER 13/09 LEL). The authors would like to thank all members of the research team including Peter G. Taylor, and team leader Ee-Ling Low, who have contributed to various components of the research. 


\section{References}

Annetta, L. A. (2008). Video games in education: Why they should be used and how they are being used. Theory into Practice, 47(3), 229-239.

http: / / dx.doi.org/10.1080/00405840802153940

Craven, R. G. \& Yeung, A. S. (2008). International best practice in effective educational interventions: Why self-concept matters and examples from bullying, peer support, and reading research. In D. M. McInerney, V. E. Shawn \& M. Dowson (Eds.), Research on sociocultural influences on motivation and learning. Vol. 8: Teaching and learning: International best practice (pp. 267-294). Greenwich, CT: Information Age.

Davidson, C. N. \& Goldberg, D. T. (2009). The future of learning institutions in a digital age. Massachusetts: Massachusetts Institute of Technology. http: / / mitpress.mit.edu / catalog/item/ default.asp?ttype=2\&tid=11841

Dawson, K. \& Heinecke, W. (2004). Conditions, processes and consequences of technology use: A case study. Technology, Pedagogy and Education, 13(1), 61-81. http: / / dx.doi.org/10.1080/14759390400200173

Demetriadis, S., Barbas, A., Molohides, A., Palaigeorgiou, G., Psillos, D., Vlahavas, I., Tsoukalas, I. \& Pombortsis, A. (2003). Cultures in negotiation: Teachers' acceptance/ resistance attitudes considering the infusion of technology into schools. Computers $\mathcal{E}$ Education, 41(1), 19-37. http: / / dx.doi.org/10.1016/S0360-1315(03)00012-5

Dias, L. B. (1999). Integrating technology. Learning \& Leading with Technology, 27(3), 10-21. [verified 10 Oct 2012]

http: / / www.tangischools.net/ TangiTech1/ documents / integrating\%20technoogy.pdf

Divaharan, S. \& Lim, C. P. (2010). Secondary school socio-cultural context influencing ICT integration: A case study approach. Australasian Journal of Educational Technology, 26(6), 741763. http:/ / www.ascilite.org.au/ ajet/ ajet26/ divaharan-2.html

Duncan-Howell, J. (2012). Digital mismatch: Expectations and realities of digital competency amongst pre-service education students. Australasian Journal of Educational Technology, 28(5), 827-840. http: / / www.ascilite.org.au / ajet/ ajet28 / duncan-howell.html

Egan, A. \& FitzGibbon, A. (2010). Preservice teachers' vision of ICT in the classroom. In D. Gibson \& B. Dodge (Eds.), Proceedings of Society for Information Technology E Teacher Education International Conference 2010 (pp. 3226-3231). Chesapeake, VA: AACE. http:// www.editlib.org/p/33871

Ertmer, P. A. (1999). Addressing first and second-order barriers to change: Strategies for technology integration. Educational Technology Research \& Development, 47(4), 47-61. http: / / dx.doi.org / 10.1007/BF02299597

Ferdig, R. \& Boyer, J. (2007). Ubiquitous computing in education: Invisible technology, visible impact. Journal of Technology \& Teacher Education, 15, 555-561. http: / / www.editlib.org/p/23518

Gonyea, R. M. (2005). Self-reported data in institutional research: Review and recommendations. New Directions for Institutional Research, 2005(127), 73-89. http:/ / dx.doi.org/10.1002 /ir.156

Graham, L. (2008). Teachers are digikids too: The digital histories and digital lives of young teachers in English primary schools. Literacy, 42(1), 10-18. http:/ / dx.doi.org/10.1111/j.14679345.2008.00476.x 
Kessler, G. \& Plakans, L. (2008). Does teachers' confidence with CALL equal innovative and integrated use? Computer Assisted Language Learning, 21(3), 269-282. http: / / dx.doi.org/ 10.1080/09588220802090303

Koh, T. S. \& Lee, S. C. (Eds.) (2008). Information communication technology in education: Singapore's ICT Masterplans 1997-2008. Singapore: World Scientific.

Lee, M. \& Gaffney, M. (Eds.) (2008). Leading a digital school. Melbourne: ACER Press.

Lee, M. \& Winzenried, A. (2009). The use of instructional technology in schools: Lessons to be learned. Victoria: ACER Press.

Lim, C. P. \& Khine, M. S. (2006). Managing teachers' barriers to ICT integration in Singapore. Journal of Technology and Teacher Education, 14(1), 97-125. http:/ / www.editlib.org/p/5339

Marsh, H. W. \& Craven, R. G. (2006). Reciprocal effects of self-concept and performance from a multidimensional perspective: Beyond seductive pleasure and unidimensional perspectives. Perspectives on Psychological Science, 1(2), 133-163. http:/ / dx.doi.org/10.1111/j.17456916.2006.00010.x

Moran, M., Hawkes, M. \& El Gayar, O. (2010). Tablet personal computer integration in higher education: Applying the unified theory of acceptance and use technology model to understand supporting factors. Journal of Educational Computing Research, 42(1), 79-101. http: / / dx.doi.org/10.2190/EC.42.1.d

Ministry of Education Singapore (2010). Speech by Ms Grace Fu, Senior Minister of State, Ministry of National Development and Ministry of Education, at the Microsoft Regional Asia Pacific Innovative Education Forum. [viewed 2 Nov 2011, verified 10 Oct 2012] http: / / www.moe.gov.sg/media/speeches / 2010/03/09/speech-by-ms-grace-fu-atmicrosoft-edu-forum.php

Ng, C., Yeung, A. S. \& Hon, R. Y. H. (2006). Does online language learning diminish interaction between student and teacher? Educational Media International, 43(3), 219-232. http: / / dx.doi.org/10.1080/09523980600641429

Pena, M. I. C. \& Yeung, A. S. (2010). Satisfaction with online learning: Does university students' computer competence matter? The International Journal of Technology, Knowledge and Society, 6(5), 97-108. http:/ / ijt.cgpublisher.com/product/pub.42/ prod.719

Robertson, M. \& Al-Zahrani, A. (2012). Self-efficacy and ICT integration into initial teacher education in Saudi Arabia: Matching policy with practice. Australasian Journal of Educational Technology, 28(7), 1136-1151. http: / / www.ascilite.org.au/ajet/ajet28/ robertson.html

Roland, C. (2010). Preparing art teachers to teach in a new digital landscape. Art Education, 63(1), $17-24$.

Pynoo, B., Devolder, P., Tondeur, J., van Braak, J., Duyck, W. \& Duyck, P. (2011). Predicting secondary school teachers' acceptance and use of a digital learning environment: A crosssectional study. Computers in Human Behavior, 27(1), 568-575. http: / / dx.doi.org/10.1016/j.chb.2010.10.005

Stevenson, O. (2008). Ubiquitous presence, partial use: The everyday interaction of children and their families with ICT. Technology, Pedagogy \& Education, 17(2), 115-130. http: / / dx.doi.org/10.1080/14759390802098615 
Swan, K., Lin, L. \& van 't Hooft, M. (2008). Teaching with (digital) technology. In C. Lassonde, R. Michael \& J. Rivera-Wilson (Eds.), Current issues in teacher education: History, perspectives and implications (pp. 171-188). Springfield,IL: Charles C. Thomas Publishing.

Swan, K., van 't Hooft, M., Kratcoski, A. \& Schenker, J. (2007). Ubiquitous computing and changing pedagogical possibilities: Representations, conceptualizations and uses of knowledge. Journal of Educational Computing Research, 36, 481-515. http: / / dx.doi.org/10.2190/B577-7162-2X11-17N5

Teo, T. (2008). Pre-service teachers' attitudes towards computer use: A Singapore survey. Australasian Journal of Educational Technology, 24(4), 413-424. http: / / www.ascilite.org.au/ajet/ajet24/teo.html

Todorova, A. \& Osburg, T. (2009). Teacher professional development for the knowledge society: The Intel® Teach Advanced Online Program. International Journal of Learning, 16(11), 73-82. http: / /ijl.cgpublisher.com/ product/pub.30/prod.2518

Wang, P. \& Chan, P. S. (1995). Advantages, disadvantages, facilitators and inhibitors of computer-aided instruction in Singapore's secondary schools. Computers E Education, 25(3), 151-162. http: / / dx.doi.org/10.1016/0360-1315(95)00048-8

Warschauer, M. \& Grimes, D. (2008). Automated writing assessment in the classroom. Pedagogies, 3(1), 22-36. http:/ / dx.doi.org/10.1080/15544800701771580

Wong, K. T., Teo, T. \& Russo, S. (2012). Influence of gender and computer teaching efficacy on computer acceptance among Malaysian student teachers: An extended technology acceptance model. Australasian Journal of Educational Technology, 28(7), 1190-1207. http:/ / www.ascilite.org.au/ajet/ajet28/wong-kt.html

Yeung, A. S., Taylor, P. G., Hui, C., Lam-Chiang, A. C. \& Low, E-L. (2012). Mandatory use of technology in teaching: Who cares and so what? British Journal of Educational Technology, in press. http: / / dx.doi.org/10.1111/ j.1467-8535.2011.01253.x

Authors: Dr Alexander Seeshing Yeung (corresponding author)

Centre for Positive Psychology and Education, University of Western Sydney

Locked Bag 1797, Penrith, NSW 2751, Australia.

Email: a.yeung@uws.edu.au

Dr Kam Ming Lim, Dr Eng Guan Tay, Mrs Audrey Cheausim Lam-Chiang and Mr Chenri Hui, National Institute of Education, Nanyang Technological University 1 Nanyang Walk, Singapore 637616.

Email: kamming.lim@nie.edu.sg, engguan.tay@nie.edu.sg,

cheausim.chiang@nie.edu.sg, chenri.hui@nie.edu.sg

Please cite as: Yeung, A. S., Lim, K. M., Tay, E. G., Lam-Chiang, A. C. \& Hui, C. (2012). Relating use of digital technology by pre-service teachers to confidence: A Singapore survey. Australasian Journal of Educational Technology, 28(8), 1317-1332.

http: / / www.ascilite.org.au/ajet/ajet28/yeung.html 